\title{
Apple peel extracts as preservation solution to maintain the quality of fresh-cut apples
}

\author{
S. Bartolini ${ }^{1}$, L. Pozzo ${ }^{2}$, F. Venturi ${ }^{3,4}$, C. Sanmartin ${ }^{3,4}$, I. Taglieri ${ }^{3}$, M. Macaluso ${ }^{3}$, A. Trivellini ${ }^{1}$, M. Orlando ${ }^{1}$, \\ A. Zinnai ${ }^{3,4}$ and A. Mensuali Sodi ${ }^{1}$ \\ ${ }^{1}$ Institute of Life Sciences, Scuola Superiore Sant'Anna, Pisa, Italy \\ ${ }^{2}$ Institute of Agricultural Biology and Biotechnology, NRC, Pisa, Italy \\ ${ }^{3}$ Department of Agriculture, Food and Environment, University of Pisa, Pisa, Italy \\ ${ }^{4}$ Interdepartmental Research Center Nutrafood-Nutraceuticals and Food for Health, University of Pisa, Pisa, Italy
}

\section{Summary}

In recent years, a wide variety of minimally processed (MP) fruits and vegetables has been worked up together with the development of synthetic additive-free or natural additive-based preservation techniques. As apple is one of the worldwide most widely consumed fruit, the objective of this research was threefold: (i) to verify the effectiveness of an innovative multi-step green process to recover high-added-value antioxidant extracts from organic apple peels. Two different extraction solvents, water or ethanol at $10 \%$, were used on apple peels; (ii) to evaluate the antimicrobial activity of extracts on MP apples; (iii) to evaluate the ability of the extracts to maintain the physicochemical attributes of fresh cut apple and assess their potentiality as alternative preservative media in comparison with traditional ones, butylated hydroxytoluene (BHT) and citric acid (CA). The extract from $10 \%$ ethanol significantly maintained fresh cut apple quality parameters (i.e., browning and texture) similarly to BHT and CA, when compared to untreated fresh cut fruits. Moreover, the apple peel extracts showed an interesting antimicrobial effect to reduce the growth of most relevant pathogenic and deteriorating both positive and negative gram bacteria.

\section{Keywords}

cryomaceration, fresh fruit, kinetic parameters, minimally processed, natural preservative, shelf-life, storage

\section{Introduction}

In recent years, a wide variety of minimally processed (MP) fruits and vegetables has been developed to respond to consumers' life style changes and demand for healthy, freshlike and easy to prepare products. However, the damage caused by MP methods (peeling, slicing, dicing, shredding, etc.) reduces the shelf life of fresh-cut products if compared to the unprocessed raw materials as a consequence of tissue softening, cut surface browning, decreased nutritional value, presence of off-flavors and microbiological spoilage during storage (Ma et al., 2017).

While the natural microflora of raw fruits and vegetables is usually non-pathogenic for humans, the product can be contaminated with pathogens from different sources

\section{Significance of this study}

What is already known on this subject?

- The consumers' lifestyle is changing and the demand for healthy, fresh-like and easy to prepare 'convenience' products constantly increases. In this context, minimally processed (MP) fruits and vegetables need preservation technologies to prolong their shelf-life. In terms of chemical-based preservatives, the use of synthetic additives could be replaced with natural ones which may be recovered from waste of processing industries. Indeed, transformation processes generate several byproducts in which bioactive compounds are still present.

What are the new findings?

- Bioactive compounds from organic apple peels (cv. 'Fuji') were extracted by a cryomaceration method, an efficient and innovative multi-step 'green' process avoiding hazardous solvents. Aqueous and $10 \%$ ethanol peel extracts were able to maintain the physicochemical attributes of fresh-cut apples (cv. 'Golden Delicious'), similarly to the traditional chemical compounds. Moreover, the apple extracts showed an antimicrobial effect against both positive and negative gram bacteria.

What is the expected impact on horticulture?

- The use of natural preservatives to retain the quality of MP fruits is important to ensure the consumption of healthier product. A circular economy perspective, the recovery and valorization of waste products can represent a promising strategy in limiting the generation of plant residues.

during growth, harvesting, transportation as well as further processing and handling. Additionally, the mechanical damage caused to cells during processing may increase the rate of tissue senescence, reducing their resistance to microbial spoilage. Many relevant pathogenic and deteriorating microorganisms, including the total and thermotolerant coliforms, Staphylococcus aureus, Salmonella spp., Listeria monocytogenes, and mesophile aerobic microorganisms were isolated from MP products and were associated with foodborne diseases or the reduced shelf life of the product (Schuh et al., 2020).

In the last decades, food scientists have been involved in the development of new technologies that can improve 
the quality and quantity of fresh-cut products with the aim to meet consumer expectations. According to Yousuf and co-workers (Yousuf et al., 2018), different approaches including surface chemical treatments and low temperature storage, have been investigated to reduce the detrimental changes such as microbial growth, desiccation and discoloration. In terms of chemical-based preservation technologies, a number of natural or synthetic preservatives have been used to prolong the shelf life of fresh-cut fruits and vegetables (Meireles et al., 2016). However, consumers have also become more critical of the use of synthetic additives, such as butylated hydroxyanisole (BHA) and butylated hydroxytoluene (BHT), as their awareness of health and food safety has increased. Thus, to maintain the quality of fresh-cut product during processing and post-harvest, the use of natural substances capable of keeping safe, and preserving the original organoleptic fresh-like characteristics is absolutely required. This has called for the use of synthetic additive-free or natural additive-based preservation techniques in recent years (Ma et al., 2017).

An interesting source of natural value-added compounds can be found in the waste derived from food processing industries (Vardanega et al., 2015). The recovery and valorization of these waste products can represent a promising strategy to manage the environmental and economic problems posed by the increasing amount of plant wastes and residues generated worldwide by food processing industries (Bartolini et al., 2020; Venturi et al., 2019).

One of the worldwide most widely consumed fruit is apple (Malus domestica Borkh.), a temperate fruit crop whose cultivation extends from continental to Mediterranean areas, with a wide range of cultivars characterized by different quality traits. In Italy only, more than 1,000 cultivars of national and local relevance have been recognized; the 70-75\% of apples are consumed as fresh fruit, while the remaining is processed into products such as juices, purées, canned wedges, dried slices, frozen wedges or cubes and, more recently, as MP products (Cerutti et al., 2013).

The transformation processes generate byproducts in which bioactive compounds are still present. In apple industry, pomace, consisting of peel, seeds, core, stems and exhausted soft tissue, has long been recognized as a valuable material for nutritional, pharmacological or cosmetic purposes, being rich in dietary fibers and polyphenols (Waldbauer et al., 2017). Moreover, from a circular economy perspective, new materials have been recently obtained from apple processing waste such as 'Appleskin ${ }^{\odot}$ ', an eco-friendly vegan leather sourced from a juicing company based in the Italian Alps and USDA certified as 'BioBased Product'.

The recovery of bioactive substances through sustainable extraction technologies are currently advisable. As an alternative to conventional methods based on the use of unsafe solvents (i.e., hexane), new technologies based on physical methods (i.e., cryomaceration, ultrasound assisted extraction, pulsed electric field, supercritical or subcritical fluids extraction, etc.) have been successfully tested (Zhang et al., 2020).

In this context, the objective of this research was threefold: (i) to verify at laboratory level the effectiveness of an innovative multi-step 'green' process to recover high-added-value antioxidant extracts from organic apple peels; (ii) to evaluate the antimicrobial activity of extracts on MP apples; (iii) to evaluate the ability of the extracts from apple peels to maintain the physicochemical attributes of fresh cut apple and assess their potential as alternative preservative media.
As further step of the research, in next future the results obtained by this preliminary study will be applied in real conditions and apple peels collected from the wastes produced during apple transformation at industrial level, will be utilized as extraction substrate.

\section{Materials and methods}

\section{Preparation of apple peels extracts}

Apple peel extracts were obtained from organic fruits of 'Fuji' (Malus domestica Borkh.), one of the commercially most important apple cultivars in the world. Apples, free from bruises and defects, were purchased from a local marketplace to have a standard and reproducible raw material, thus avoiding the variables deriving from the apple transformation process. Fruits were then washed under running water, peels (about $1 \mathrm{~mm}$ of thickness) were removed manually from the whole fruit by a ceramic knife to avoid oxidation and immediately stored in inert atmosphere $\left(\mathrm{N}_{2}\right)$. The extraction method was carried out on the basis of the procedure performed on potato peels and described in a previous paper (Bartolini et al., 2020; Venturi et al., 2019). To ensure homogeneity among the samples used for the different extractions runs, the peels collected from different fruits were further mixed before the extraction.

In particular, the peels were stored in a stainless-steel vat provided with devices for the automated temperature control and maintained in direct contact with solid $\mathrm{CO}_{2}$ (ratio peels $/ \mathrm{CO}_{2, s}=1 / 1 \mathrm{w} / \mathrm{w}$ ) over a period of 24 hours. The cryomaceration was stopped by the increasing of the temperature thus promoting a controlled defrosting phase in inert atmosphere $\left(\mathrm{N}_{2}\right.$ flow).

To optimize the best operating conditions to be adopted, we utilized two different solvent solutions: distilled water (named AW) or 10\% ethanol solution (named AEt). $20 \mathrm{~g}$ of apple peels, previously cryomacerated and defrosted, have been subjected to solid/liquid extraction with the selected solvent for 24 hours in the dark and inert atmosphere (ratio $1 / 20 \mathrm{w} / \mathrm{w}, \mathrm{T}=27^{\circ} \mathrm{C}$, stirring rate $=650 \mathrm{rpm}$, atmosphere $=$ $\mathrm{N}_{2} 100 \%$ ). All the extracts were filtered under vacuum and maintained in inert atmosphere $\left(\mathrm{N}_{2}\right)$ at $\mathrm{T}=-20^{\circ} \mathrm{C}$ until analysis.

\section{Determination of total phenols and antioxidant capacity}

The total phenols content of both the extracts were determined colorimetrically at $700 \mathrm{~nm}$, using the Folin-Ciocalteu method with slight modifications (Venturi et al., 2015): in a 100 -mL flask, $60 \mathrm{~mL}$ of deionized water, $1 \mathrm{~mL}$ of each extract were added and mixed with $5 \%$ of Folin and $15 \%$ of sodium carbonate (20\%). After a waiting phase of $30 \mathrm{~min}$ the samples were ready for the spectrophotometric reading at $700 \mathrm{~nm}$.

Moisture content of apple peels was determined according to standard AOACS methods (AOACS International, 2019) and the values of gallic acid equivalent (Liu et al., 2019) were used to represent the phenolic content as $\mathrm{mg} \mathrm{kg}^{-1} \mathrm{dw}$. The antioxidant power (Trolox equivalent antioxidant capacity (TEAC) of the extracts was determined according to Venturi and co-workers (2019). The radical solution was diluted in water to obtain at $734 \mathrm{~nm}$ an absorbance of $0.70 \pm 0.05$. After $5 \mathrm{~min}$ from the addition of the extract $(1 \% \mathrm{v} / \mathrm{v})$, the decrease in absorbance was monitored and compared to that of the Trolox standard. The activities of the extracts were quantified by using a dose-response curve of Trolox in the 0.2$1.5 \mathrm{mM}$ range, expressing them in terms of Trolox equivalent antioxidant capacity (TEAC) $\mathrm{L}^{-1}$ extract. 


\section{Antimicrobial activity of apple peels extracts}

1. Bacteria strains preparation. The bacterial strains were supplied by the American type culture collection (ATCC). The antimicrobial activity of each extract was studied on three gram negative bacteria, specifically Escherichia coli (ATCC 25922), Salmonella enterica ser. typhimurium (ATCC 14028), and Enterobacter aerogenes (ATCC 13048), and two gram positive bacteria, Enterococcus faecalis (ATCC 29212) and Staphylococcus aureus (ATCC 25923). All the bacteria strains were cultured in Muller Hilton broth (MHB) (Merck, Germany) at $37^{\circ} \mathrm{C}$ for $24 \mathrm{~h}$.

2. Antimicrobial activity. The percentage of growth inhibition of selected bacteria exerted by the AW and AEt apple peel extracts was determined according to Delgado-Adámez et al. (2012), with some modifications.

The tested bacteria were cultured in $\mathrm{MHB}$ at $37^{\circ} \mathrm{C}$ for 16 hours and diluted to match the turbidity of $0.5 \mathrm{McF}$ arland standard. An aliquot of $50 \mu \mathrm{L}$ of bacterial suspensions (about $1-5 \times 10^{5} \mathrm{CFU} \mathrm{mL}^{-1}$ ) was added to $100 \mu \mathrm{L}$ of MHB and to $100 \mu \mathrm{L}$ of AW or AEt (diluted up to $0,7.5,10,15,20$ and $25 \mathrm{mg} \mathrm{mL}^{-1}$ with water and $10 \%$ ethanol, respectively) in a 96-well plate. A negative control of $100 \mu \mathrm{L}$ of water or $10 \%$ ethanol was included on each microplate. The plates were incubated at $37^{\circ} \mathrm{C}$ for 24 hours in aerobic conditions. Afterwards, the optical density at $630 \mathrm{~nm}$ was determined by a microplate reader (Victor X3 2030 multilabel counter, Perkin Elmer, U.K.). The percentage of growth inhibition was calculated as follows:

$$
\text { Final growth }(\%)=(\text { ODS } / O D C) \times 100
$$

where ODS is the optical density of the sample and ODC is the optical density of the control.

\section{Fresh-cut apples preparation}

Organic apples (Malus domestica Borkh. cv. 'Golden Delicious') were used to prepare MP product according to safety statements and recommendations for MP apples (Dávila-Aviña et al., 2015). Fruits were peeled, cored, and cut into cubes (about $2 \mathrm{~cm}^{3}$ ) which were dipped for $2 \mathrm{~min}$ in different preservative solutions. At this step apple peel extracts were applied. Samples were dipped in distilled water (control) or in BHT or in CA (citric acid) solutions. The choice fell on the CA for its proved effectiveness in different apple cultivars as acidulant and chelating agent (Rojas-Graü et al., 2006), and on the BHT, an organic compound, chemically a phenol derivative. This latter is useful for its antioxidant properties and authorized as a food preservative, although there is debate whether BHT exposure is linked to cancer, asthma, and behavioral issues in children (Wang and Kannan, 2019).
The composition of different tested dipping solutions are summarized in Table 1. After dipping, apple cubes were gently dried with absorbent paper, randomly selected and packaged in plastic lidded containers (three cubes in each container, $150 \mathrm{cc}$ volume, Cuki ${ }^{\circledR}$, Turin, Italy) with air as storage atmosphere. The packages, under normal atmospheric conditions, were stored differently to assess the quality maintenance of fresh-cut apples: i) room conditions $\left(20 \pm 1^{\circ} \mathrm{C}\right.$, in the light), 3 hours after the dipping treatments, checking for the first symptoms of browning reaction (quick test); ii) cold storage $\left(4 \pm 1^{\circ} \mathrm{C}\right.$ in the dark), 2 and 5 days long from dipping treatments, to simulate the standard retail storage conditions. Each dipping treatment consisted of 3 replicates represented by different containers.

\section{Quality measurements on fresh-cut apples}

Changes of the main quality parameters limiting the shelf-life of fresh-cut apples, such as surface browning, flesh firmness and total soluble solids content, were checked over the different tested conditions.

Color of apple cube surfaces was measured using a colorimeter (Eoptis, Mod. CLM-196 Benchtop, Italy).

According to Colás-Medà et al. (2016), the results were expressed as $\Delta$ Browning Index $(\Delta \mathrm{BI})$ values by the following equation:

$$
\mathrm{BI}=100 *(\mathrm{x}-0.31) / 0.172
$$

where

$$
\mathrm{x}=\left(a^{*}+1.75 L^{*}\right) /\left(5.645 L^{*}+a^{*}-3.012 b^{*}\right)
$$

and

$$
\Delta \mathrm{BI}=\mathrm{BI}_{\mathrm{f}}-\mathrm{BI}_{\mathrm{s}}
$$

where:

$L^{*}$ defines the lightness, $a^{*}$ and $b^{*}$ define the red-greenness and blue-yellowness, respectively;

$\mathrm{BI}_{\mathrm{f}}=\mathrm{BI}$ at the end of each observation time;

$\mathrm{BI}_{\mathrm{s}}=\mathrm{BI}$ at the start of each experiment.

Total soluble solids content (TSS) was determined on fresh tissue juice of apple cubes using a hand refractometer (Mod. 2369-Bertuzzi, Milan, Italy) and results were expressed as ${ }^{\circ}$ Brix.

Flesh firmness of the apple cubes was tested using a manual penetrometer (Mod. 53205, TR Turoni \& C. snc, Forlì, Italy), equipped with a metal probe (8-mm diameter). The probe penetrated $3 \mathrm{~mm}$ into the cube and the force needed to break parenchyma cells in the cortex was expressed in $\mathrm{N} \mathrm{cm}^{-2}$.

TABLE 1. Preservative media used for dipping of fresh-cut apple cubes: standard compounds, butylated hydroxytoluene (BHT) and citric acid (CA); novel compounds: water (AW) and ethanol 10\% (AEt) extracts from apple peels and distilled water (W) as control.

\begin{tabular}{llc}
\hline Code & Solution composition & Solution pH \\
\hline W (Control) & Distilled water & 7.00 \\
\hline Standard compounds & & 7.75 \\
BHT & $1 \%$ butylated hydroxytoluene & 2.01 \\
CA & $1 \%$ citric acid & 4.70 \\
\hline Novel compounds & & 4.76 \\
AEt & $10 \%$ ethanol extract in distilled water 1:1 (v:v) \\
AW & Water extract in distilled water 1:1 (v:v) & \\
\hline
\end{tabular}




\section{Statistical analysis}

Statistical analysis was carried out by GraphPadPrism (v. 5.00 for Windows, GraphPad Software, La Jolla, San Diego, CA, U.S.A.). Data are reported as mean values \pm SE (standard error). Student $t$-test or analysis of variance (ANOVA) were performed at least at the significant level of $p \leq 0.05$. Differences detected by ANOVA were separated by Tukey multiple means comparison test. Kinetic parameters $\left(\mathrm{k}_{\mathrm{P}}\right.$ and $[\mathrm{P}]_{\mathrm{t}=\infty}$ ) and their confidence intervals (c.i.; $p \leq 0.05$ ) were calculated by the statistical program Burenl (Venturi et al., 2017).

\section{Results and discussion}

\section{Characteristics of apple peel extracts}

The content of bioactive compounds in apples can be influenced by genetic, pre- and post-harvest factors such as cultivar, growing area, agronomical managements and storage conditions. Among different cultivars, a high variability has been found based on phenolic contents; in particular, 'Fuji' apples showed a medium level of antioxidant power, mainly in the skin (Bartolini and Ducci, 2017). The extraction yield of phytochemicals may be influenced by the solvent composition as well as the adopted process (Albishi et al., 2013).

The cryomaceration of plant byproducts by means of solid carbon dioxide has been identified as a successfully method to improve the extraction yield of bioactive compounds from different raw products by adopting green solvents (Ascrizzi et al., 2019; Sanmartin et al., 2019). This approach has proved to be suitable for the extraction of phenolic compounds from potato peels (Vardanega et al., 2015).

As previously reported (Zinnai et al., 2011), during extraction the concentration of the phenolic compounds $\left([\mathrm{P}]_{\mathrm{t}=\mathrm{t}}\right)$ in the liquid phase, increased with maceration time to reach an asymptotic maximum value.

According to Eq. 5, the accumulation rate of the phenolic compounds $\left(\mathrm{d}[\mathrm{P}]_{\mathrm{t}=\mathrm{t} / \mathrm{dt}}\right)$ can be assumed as directly proportional to the difference occurring between their asymptotic maximum value $\left([\mathrm{P}]_{t=\infty}\right)$ and the phenolic concentration $\left([\mathrm{P}]_{\mathrm{t}=\mathrm{t}}\right)$ extracted in the liquid phase at a random time $\mathrm{t}=\mathrm{t}$ :

$$
\mathrm{d}[\mathrm{P}]_{\mathrm{t}=\mathrm{t} / \mathrm{dt}}=\mathrm{k}_{\mathrm{p}} \cdot\left([\mathrm{P}]_{\mathrm{t}=\infty}-[\mathrm{P}]_{\mathrm{t}=\mathrm{t}}\right)
$$

After integration, the Eq. 6 allows to calculate the concentration of phenolic compounds extracted $\left([\mathrm{P}]_{t=t}\right)$ from the cryomacerated apple peels at any maceration time $(\mathrm{t}=\mathrm{t})$ :

$$
[\mathrm{P}]_{\mathrm{t}=\mathrm{t}}=[\mathrm{P}]_{\mathrm{t}=\infty} \cdot\left(1-\mathrm{e}^{-\mathrm{kP} \cdot \mathrm{t}}\right)
$$

where:

$\mathrm{k}_{\mathrm{P}}=$ kinetic constant, that can be assumed as a reliable measure of the initial rate of the extractive process;

$[\mathrm{P}]_{\mathrm{t}=\infty}=$ asymptotic value that can be assumed by the concen- tration of total phenols when the extraction time is close to infinite.

The values of both kinetic parameters $\left(\mathrm{k}_{\mathrm{P}}\right.$ and $\left.[\mathrm{P}]_{\mathrm{t}=\infty}\right)$ and their confidence intervals (c.i.; $p \leq 0.05$ ), calculated by the statistical program Burenl (Venturi et al., 2017) are reported in Table 2. The high values assumed by the squared correlation coefficient, confirm the suitability of the kinetic equations adopted as well as the reliability of the hypothesis introduced.

As shown in Table 2, in the adopted experimental conditions the kinetics extraction appeared the same regardless the solvent utilized, while the significantly higher values in terms of both total phenols extracted and antioxidant power were obtained when ethanol was added in the extraction mix. By 10\% ethanol solvent, phenols, and antioxidant power increase of about $40 \%$ and more than two-fold, respectively, compared to those of water extract. The presence of a low quantity of ethanol enabled to improve the profitability of the extraction process, in agreement with literature reporting the ethanol aqueous solutions as the most utilized, like methanol and acetone as well (Contini et al., 2008).

Thus, apple peels could be of similar interest to other crude extracts used as natural preservatives and obtained from raw materials rich in phenolics, such as fruits, herbs, vegetables, cereals.

\section{Antimicrobial activity of apple peel extracts}

The antimicrobial activity on selected gram positive (Figure 1) and gram negative (Figure 2) enteric bacterial strains was evaluated as final growth in the presence of increasing concentrations of AW and AEt. The results are expressed as final percentage of growth and compared to controls.

For gram positive bacteria (Figure 1), the lowest concentrations that were able to inhibit the final growth of Staphylococcus aureus were $15 \mathrm{mg} \mathrm{mL}^{-1}$ for both AW (78.82 $\pm 5.38 \%)$ and AEt $(74.45 \pm 8.78 \%)$ and for Enterococcus faecalis $10 \mathrm{mg} \mathrm{mL}^{-1}$ for AW (86.43 $\left.\pm 7.66 \%\right)$ and $15 \mathrm{mg} \mathrm{mL}^{-1}$ for AEt $(79.16 \pm 2.41 \%)$.

For gram negative bacteria (Figure 2), the lowest concentrations that were able to inhibit the final growth of Salmonella typhimurium were $15 \mathrm{mg} \mathrm{mL}^{-1}$ for AW $(86.56 \pm 12.21 \%)$ and $10 \mathrm{mg} \mathrm{mL}^{-1}$ for AEt $(91.94 \pm 5.35 \%)$, and for Escherichia coli $10 \mathrm{mg} \mathrm{mL}^{-1}$ for AW $(87.61 \pm 1.40 \%)$ and $15 \mathrm{mg} \mathrm{mL}^{-1}$ for AEt (83.42 $\left.\pm 6.97 \%\right)$, and for Enterobacter aerogenes $25 \mathrm{mg} \mathrm{mL}^{-1}$ for $\mathrm{AW}(76.91 \pm 1.54 \%)$ and $15 \mathrm{mg} \mathrm{mL}^{-1}$ for AEt $(82.19 \pm 3.81 \%)$.

The antimicrobial activity of polyphenols occurring in vegetable foods has been extensively investigated against a wide range of microorganisms. Many mechanisms of antimicrobial action have been suggested such as damage to the bacterial membrane, and suppression of some virulence factors, including enzymes and toxins (Barbieri et al., 2017).

TABLE 2. Kinetic parameters $\left(\mathrm{k}_{\mathrm{p}}\right.$ and $\left.[\mathrm{P}]_{\mathrm{t}=\infty}\right)$ of the extraction process as a function of the solvent utilized. Antioxidant power of the extracts (Trolox equivalent antioxidant capacity, $\mu \mathrm{m}$ TEAC $\mathrm{mL}^{-1}$ ) obtained from apple peels using water and $10 \%$ ethanol as extraction solvents. Data are means \pm SE. In the columns, asterisks indicate significant differences between solvents according to Student $t$ test $(p \leq 0.05)$.

\begin{tabular}{lcccc} 
Extraction solvent & $R^{2}$ & $\begin{array}{c}k_{\mathrm{p}} \pm \text { c.i. } \\
\left(\mathrm{min}^{-1}\right)\end{array}$ & $\begin{array}{c}{[\mathrm{P}]_{\mathrm{t}=\infty}} \\
{[\mathrm{gallic} \text { acid }]} \\
\left(\mathrm{mg} \mathrm{kg}^{-1} \mathrm{~d} . \mathrm{m} .\right)\end{array}$ & $\begin{array}{c}\text { Antioxidant power } \\
\left(\mu \mathrm{m} \mathrm{TEAC} \mathrm{mL}^{-1}\right)\end{array}$ \\
\hline Water & 0.97 & $0.010 \pm 0.01$ & $9.25 \pm 0.26$ & $0.33 \pm 0.03$ \\
$10 \%$ ethanol & 0.97 & $0.011 \pm 0.01$ & $13.14 \pm 0.20^{*}$ & $0.73 \pm 0.02^{*}$ \\
\hline
\end{tabular}






FIGURE 1. Effect of water (AW) and ethanol $10 \%$ (AEt) peel extracts at different concentrations $(7.5,10,15,20$ and $25 \mathrm{mg} \mathrm{mL}^{-1}$ ) on gram positive bacteria growth: Staphylococcus aureus ATCC 25923 (A), Enterococcus faecalis ATCC 29212 (B). Bars with different letters are statistically different at $p<0.05$. Lower cases refer to AW and upper cases to AEt. Different lower-case letters indicate a significant difference among different concentrations of AW, and different capital letters indicate a significant difference among different concentrations of AEt $(p<0.05)$. Results are reported as means $(n=3)$ values \pm SD.

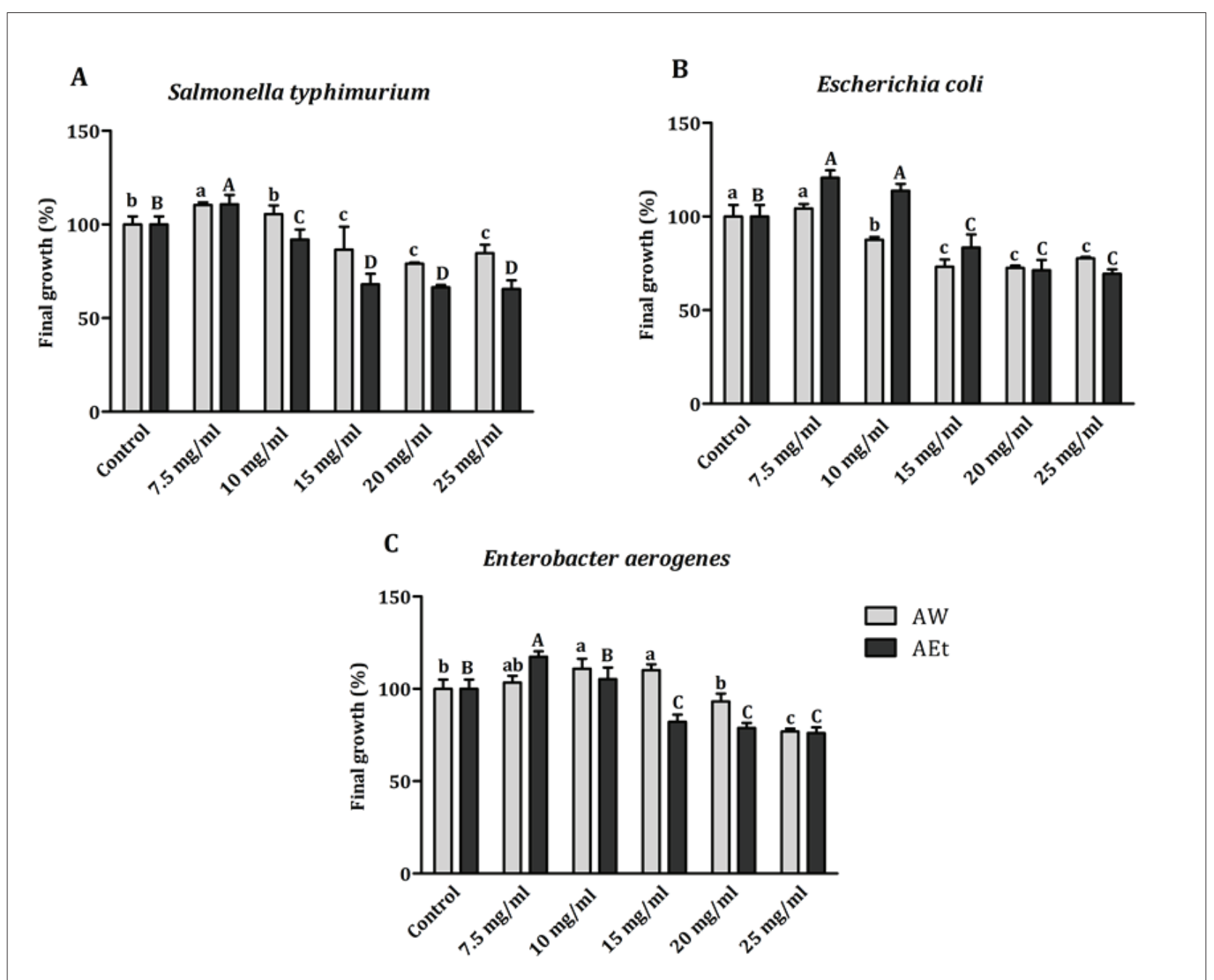

FIGURE 2. Effect of water (AW) and ethanol 10\% (AEt) peel extracts at different concentrations $(7.5,10,15,20$ and $25 \mathrm{mg} \mathrm{mL}^{-1}$ ) on gram negative bacteria growth: Salmonella typhimurium ATCC 14028 (A), Escherichia coli ATCC 25922 (B), and Enterobacter aerogenes ATCC 13048 (C). Lower cases refer to AW and upper cases to AEt. Different lower-case letters indicate a significant difference among different concentrations of $\mathrm{AW}$, and different capital letters indicate a significant difference among different concentrations of AEt $(p<0.05)$. Results are reported as means $(n=3)$ values \pm SD. 
TABLE 3. Effect of the water (AW) and ethanol 10\% (AEt) extracts at the highest concentration of $25 \mathrm{mg} \mathrm{mL}^{-1}$ on gram positive and negative bacteria growth inhibition (\%). Results are reported as means values \pm standard deviation. Significant differences within each species were determined according to a Student $t$ test.

\begin{tabular}{lccc}
\hline Treatment & p & AW & AEt \\
\hline Staphylococcus aureus & $<0.0001$ & $13.14 \pm 1.31$ & $31.21 \pm 1.25$ \\
Enterococcus faecalis & n.s. & $19.23 \pm 1.89$ & $18.27 \pm 6.48$ \\
Salmonella typhimurium & $<0.01$ & $15.37 \pm 4.53$ & $34.46 \pm 4.79$ \\
Escherichia coli & $<0.01$ & $22.31 \pm 0.75$ & $30.56 \pm 2.33$ \\
Enterobacter aerogenes & n.s. & $23.09 \pm 1.54$ & $23.99 \pm 3.19$ \\
\hline
\end{tabular}

Moreover, a direct comparison between the effect of the AW and AEt on the growth inhibition (\%) of gram positive and gram-negative bacteria was made at the higher concentrations of extracts ( $25 \mathrm{mg} \mathrm{mL}^{-1}$ ) (Table 3 ).

AEt was significantly more efficient than AW to inhibit the growth of Staphylococcus aureus $(p<0.0001)$, Salmonella typhimurium $(p<0.01)$ and Escherichia coli $(p<0.01)$, probably due to the higher phenolic content together with the antimicrobial effect of the ethanol solution.

Authors (Alberto et al., 2006) studied the antimicrobial effect of polyphenols from different extracts from apple peel on human bacterial pathogens and showed that Escherichia coli ATCC 25922, P. aeruginosa ATCC 27853 and Staphylococcus aureus ATCC 29213 were the most susceptible microorganisms, whereas Escherichia coli ATCC 35218 and Escherichia coli were the most resistant bacteria regarding the apple peel extracts. Other authors (Fratianni et al., 2011) demonstrated that the ethanolic extract of peels from the apple cultivar 'Annurca' clearly exhibited antimicrobial activity against Bacillus cereus and Escherichia coli serotype 0157:H7 but no activity was observed against Staphylococcus aureus. In a study conducted with propolis ethanolic extracts significant antimicrobial activity was shown against gram positive (minimum inhibitory concentrations between $7.8 \mathrm{mg} \mathrm{mL}^{-1}$ and $12.5 \mathrm{mg} \mathrm{mL}^{-1}$ ) while gram negative were less susceptible (minimum inhibitory concentrations between $12.5 \mathrm{mg} \mathrm{mL}^{-1}$ and $50 \mathrm{mg} \mathrm{mL}^{-1}$ ) (Stepanović et al., 2003). Another study conducted to evaluate the antimicrobial properties of extracts of thirty types of commercial herbs and spices commonly used in the production of ready meals against Escherichia coli, Listeria innocua, Staphylococcus aureus and Pseudomonas fluorescens demonstrated relatively strong antimicrobial activity against all bacteria tested from ethanol and hexane extracts of oregano, clove, sage, rosemary and celery with MICs ranging between 2.5 and $40 \mathrm{mg} \mathrm{mL}^{-1}$ (Witkowska et al., 2013).

\section{Quality measurements on fresh-cut apples}

1. Room condition storage. The immediate physical effect consequently to wounding causes a mechanical shock to tissues that, later, starts to respond physiologically (Saltveit, 2016). The main deterioration after physical damage in fresh apples is due to the browning of the flesh tissue that reduces appearance, organoleptic properties, and nutritional quality (Chiabrando and Giacalone, 2012). Fruits and vegetables brown rapidly when injured tissues are exposed to $\mathrm{O}_{2}$ in the air; this is due to the oxidation of pre-existing phenols to ortho-quinones, which in turn quickly polymerize to form brown pigments (Saltveit, 2016). In certain apple cultivars, like 'Golden Delicious', the oxidation processes on the surface and in the under layer of flesh tissue occur very early after cut (Bartolini et al., 2020).

A preliminary and quick test ( $3 \mathrm{~h}$ at $\left.20 \pm 1^{\circ} \mathrm{C}\right)$ to evalu- ate whether the apple peel extracts were able to slowdown the oxidation process was developed. A comparison between dipping treatments using apple peel extracts and standard preservative solutions, such as BHT and CA, was carried out.

Results on the flesh browning (Figure 3 ) were expressed as percentage of $\Delta$ browning index $(\Delta \mathrm{BI})$. All the preservative agents, used as dip treatments, significantly reduced the flesh browning severity in comparison with the control (W). The CA treatment had the strongest anti-browning effect, showing a $\Delta \mathrm{BI}$ value close to zero due to its known effect in browning preventing (Bartolini et al., 2020; Venturi et al., 2019). The AW extracts showed analogous values to the chemical compound BHT, while the AEt treatment induced a more important anti-browning effect on apple cubes (Figure $3)$.

2. Refrigerated storage conditions. MP apples require storage temperatures not exceeding $4-6^{\circ} \mathrm{C}$ and need stabilizing treatments to maintain product quality during cold storage (Putnik et al., 2017). Consequently, the use of conservative compounds must be appropriately tested also under cold conditions to ensure the results are relevant for the supply chain.

After 2 and 5 days of cold storage $\left(4^{\circ} \mathrm{C}\right)$, the degree of browning, firmness and TSS of flesh was assessed.

As regards flesh browning (Table 4), the $\Delta \mathrm{BI}$ percentage ranged from about 30 to $54 \%$ after 2 days of storage. Minimum values were recorded for AEt extracts which had an activity like CA; maximum percentages were shown by $\mathrm{W}$



FIGURE 3. Browning quick test. Effect of dipping treatments on flesh browning of fresh-cut apples, expressed as $\Delta$ in browning index percentage $(\% \Delta \mathrm{BI})$ after 3 hours at room temperature $\left(20 \pm 1^{\circ} \mathrm{C}\right)$. Dipping treatments: $\mathrm{W}$ (water); BHT (1\% butylated hydroxytoluene); CA (1\% citric acid); AEt (10\% ethanol apple extract); AW (water apple extract). Data are means \pm SE. 
TABLE 4. Percentage change in browning index (\% $\Delta \mathrm{BI})$ of fresh-cut apple cubes after 2 and 5 days of cold storage $\left(4^{\circ} \mathrm{C}\right)$, after treatment with traditional preservatives butylated hydroxytoluene (BHT) and citric acid (CA) or innovative preservatives water (AW) and ethanol 10\% (AEt) extracts from apple peels, and (W) distilled water as control. Mean values marked with different letters within each column (ANOVA and Tukey post-hoc test) or by an asterisk within each row (Student $t$ test) are significantly different at $p \leq 0.05$.

\begin{tabular}{lll}
\hline Treatment & $\% \Delta \mathrm{BI}$ day 2 & $\% \Delta \mathrm{BI}$ day 5 \\
\hline W & $53.99 \pm 4.78 \mathrm{ab}$ & $53.65 \pm 2.95 \mathrm{~b}$ \\
BHT & $40.65 \pm 1.63 \mathrm{~b}$ & $57.67 \pm 3.00 \mathrm{a}^{*}$ \\
CA & $38.22 \pm 2.00 \mathrm{c}$ & $53.07 \pm 1.89 \mathrm{~b}^{*}$ \\
AEt & $30.05 \pm 4.14 \mathrm{c}$ & $54.86 \pm 2.66 \mathrm{~b}^{*}$ \\
AW & $54.72 \pm 3.18 \mathrm{a}$ & $67.21 \pm 0.19 \mathrm{a}^{*}$ \\
\hline
\end{tabular}

and by AW-extracts. As expected, after 5 days of cold storage, a general deterioration was observed; the $\Delta \mathrm{BI}$ of apple cubes treated with $\mathrm{W}$ only remained unchangeable while in all other dipping treatments significant increases from 15 to 22\% were observed.

The relationship \% $\Delta \mathrm{BI}$ obtained at room temperature after $3 \mathrm{~h}$ from dipping, and $\Delta \mathrm{BI}$ after 2 days of cold storage at $4^{\circ} \mathrm{C}$ (Figure 4$)$ indicates a good fit $\left(\mathrm{R}^{2}=0.7498\right.$, significant at $\alpha=0.05$ ), suggesting the quick test is a suitable method to determine the effectiveness of treatments with novel compounds. Despite the fact that cold storage induces an increase in fruit tissue browning, the quick test results from the first hours after sample preparation at room temperature can be considered as a good guide for the treatment responses observed during cold storage as also suggested by Augusto et al. (2016).

According to the cultivar, apples are characterized by a different fruit flesh texture at harvest, and this parameter regulates the postharvest storability and quality of stored apples over time. Thus, the maintenance of flesh firmness in MP apples is a quality key attribute to preserve over storage time.

At the preparation time of apple cubes $(d=0)$, the flesh firmness measured about $29 \mathrm{~N} \mathrm{~cm}^{-2}$ (Table 5). After 2 days of cold storage at $4^{\circ} \mathrm{C}$, significant differences were found among

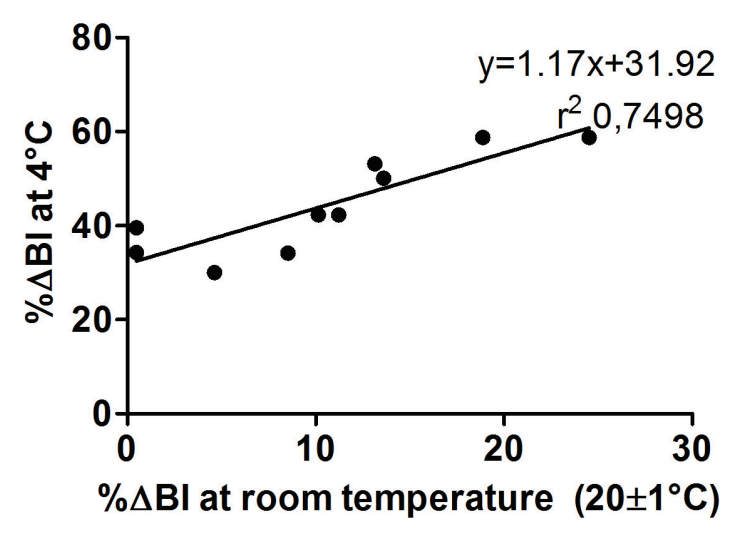

FIGURE 4. Relationship between $\Delta$ in browning index percentage $(\% \Delta \mathrm{BI})$ measured for apple cubes maintained for 2 hours at room temperatures and after 2 days cold storage at $4^{\circ} \mathrm{C}$.
TABle 5. Firmness $\left(\mathrm{N} \mathrm{cm}^{-2}\right)$ of fresh-cut apple cubes after 2 and 5 days of cold storage $\left(4^{\circ} \mathrm{C}\right)$ after treatment with traditional preservatives butylated hydroxytoluene (BHT) and citric acid (CA) or innovative preservatives water (AW) and ethanol 10\% (AEt) extracts from apple peels, and (W) distilled water as control. Mean values marked with different letters within each column (ANOVA) or by an asterisk within each row (Student $t$ test) are significantly different at $p \leq 0.05$.

\begin{tabular}{llc}
\hline \multirow{2}{*}{ Treatment } & \multicolumn{2}{c}{ Initial firmness at day $0=29.91 \pm 1.56 \mathrm{~N} \mathrm{~cm}^{-2}$} \\
\cline { 2 - 3 } & \multicolumn{1}{c}{ Day 2 } & Day 5 \\
\hline W & $19.90 \pm 0.78 \mathrm{c}$ & $19.02 \pm 0.29 \mathrm{~b}$ \\
BHT & $30.00 \pm 0.98 \mathrm{ab}$ & $26.08 \pm 0.78 \mathrm{a}^{*}$ \\
CA & $33.34 \pm 2.74 \mathrm{a}$ & $24.22 \pm 0.68 \mathrm{a}^{*}$ \\
AEt & $26.67 \pm 0.58 \mathrm{~b}$ & $23.33 \pm 0.98 \mathrm{a}^{*}$ \\
AW & $26.87 \pm 0.58 \mathrm{ab}$ & $24.81 \pm 1.07 \mathrm{a}^{*}$ \\
\hline
\end{tabular}

TABLE 6. Total soluble solids content (TSS) of fresh tissue juice of apple cubes ( ${ }^{\circ}$ Brix) after 2 and 5 days of cold storage $\left(4^{\circ} \mathrm{C}\right)$ after treatment with traditional preservatives butylated hydroxytoluene (BHT) and citric acid (CA) or innovative preservatives water (AW) and ethanol 10\% (AEt) extracts from apple peels, and (W) distilled water as control. Mean values marked with different letters within each column (ANOVA) or by an asterisk within each row (Student $t$ test) are significantly different at $p \leq 0.05$.

\begin{tabular}{lrr}
\hline \multirow{2}{*}{ Treatment } & \multicolumn{2}{c}{ Initial TSS at day $0=13 \pm 0.29^{\circ}$ Brix } \\
\cline { 2 - 3 } & \multicolumn{1}{c}{ Day 2} & Day 5 \\
\hline W & $12 \pm 0.29 \mathrm{a}$ & $10 \pm 0.28 \mathrm{~b}^{*}$ \\
BHT & $9 \pm 0.28 \mathrm{~b}$ & $9.17 \pm 0.44 \mathrm{~b}$ \\
CA & $9 \pm 0.30 \mathrm{~b}$ & $10 \pm 0.28 \mathrm{~b}$ \\
AEt & $12 \pm 0.30 \mathrm{a}$ & $12 \pm 0.28 \mathrm{a}$ \\
AW & $11 \pm 0.28 \mathrm{a}$ & $10 \pm 0.29 \mathrm{~b}$ \\
\hline
\end{tabular}

dipping treatments. Apples dipped in water showed the largest firmness decrease reaching about $20 \mathrm{~N} \mathrm{~cm}^{-2}$, a $33 \%$ reduction in comparison to the initial value. Dipping treatments with the innovative preservatives from apple peel extracts showed much less flesh softening (about 6-9\%) with values comparable with the BHT. As expected, after 5 days of storage a significant softening of mesocarp tissues was recorded in all treatments, but maintaining a higher firmness in comparison with the control (W); however, in samples dipped in AEt and AW extracts the firmness decrease rate was similar to BHT and CA. This pattern highlights the capacity of the tested apple peel derived compounds to exert a positive influence, delaying a loss of textural integrity. Peel extracts contain important elements (Chinnici et al., 2004), because apples are considered a good source of minerals, including calcium ions (Manzoor et al., 2012). This element could exert an influence on the pectin chains stability and on the cell cohesion (Ortiz et al., 2011).

'Golden Delicious' apples used in this experimental trial were characterized by a TSS of about $13^{\circ}$ Brix. In Table 6 the TSS changes of apple cubes after 2 and 5 days at cold storage $\left(4^{\circ} \mathrm{C}\right)$ are shown. After the shortest storage time, a small reduction in TSS, in comparison with the initial value, was measured in apples dipped in AEt and AW extracts, and W. The largest change (from 13 to $9^{\circ} \mathrm{Brix}$, about 30\%) was recorded in samples treated with BHT and CA dipping solu- 
tions. Analyses carried out after 5 days of storage denoted a generally unvaried value in cubes treated with apple peel extracts, suggesting a protective effect in minimizing carbohydrate breakdown, while the TSS level significantly decreased in cubes dipped solely in water. This was in accordance with another study reporting no substantial changes in apple slices of cv. 'Gala' coated with alginate and stored at $5^{\circ} \mathrm{C}$ with values ranging from 14.6 to $12.8^{\circ} \mathrm{Brix}$ (Olivas et al., 2007).

\section{Conclusions}

In the processing of MP fruits and vegetables, a growing interest in replacing synthetic additives with natural ones has arisen in recent years. Moreover, particular attention has been addressed in the recovery of antioxidant compounds from processing industry waste, in a circular economy perspective. In this regard, the results obtained in this experiment suggest the possibility to apply the cryomaceration methods as valuable 'green' approach to obtain useful extracts from apple peels, avoiding hazardous solvents. Between the two extracts tested, AEt resulted in a significant influence on the maintenance of quality parameters. A satisfactory anti-browning effect was verified, similar to the chemicals BHT and CA which are usually used as antioxidants in MP products.

Moreover, the apple extracts showed an interesting antimicrobial effect by reducing the growth of most relevant pathogenic and saprophytic bacteria, both gram positive and negative, that can be isolated from fresh-cut products.

In conclusion, this study shows the value of 'Fuji' apple peels as promising sources of raw materials for potential natural additives. Nowadays, the use of these natural preservatives to help retain the quality of MP fruits is important to ensure the consumption of products with high nutritional values, considering an increasing demand from consumers for healthier foods.

\section{Acknowledgments}

This work was supported by the project "I residui della trasformazione dell'orto-frutta: da 'scarto' a 'risorsa' per il recupero di composti fitochimici naturali" from the MiPAAFT (Italian Ministry "Politiche Agricole Alimentari, Forestali e del Turismo").

\section{References}

Alberto, M.R., Rinsdahl Canavosio, M.A., and Manca De Nadra, M.C. (2006). Antimicrobial effect of polyphenols from apple skins on human bacterial pathogens. Electron. J. Biotechnol. 9, 205-209. https://doi.org/10.2225/vol9-issue3-fulltext-1.

Albishi, T., John, A., and Al-khalifa, A.S. (2013). Phenolic content and antioxidant activities of selected potato varieties and their processing by-products. J. Funct. Foods 5, 590-600. https://doi. org/10.1016/j.jff.2012.11.019.

AOACS International (2019). Official Methods of Analysis (Rockville, U.S.A.).

Ascrizzi, R., Taglieri, I., Sgherri, C., Flamini, G., Macaluso, M., Sanmartin, C., Venturi, F., Quartacci, M.F., Pistelli, L., and Zinnai, A. (2019). Nutraceutical oils produced by olives and citrus peel of Tuscany varieties as sources of functional ingredients. Molecules 24 , 65. https://doi.org/10.3390/molecules24010065.

Augusto, A., Simões, T., Pedrosa, R., and Silva, S.F.J. (2016). Evaluation of seaweed extracts functionality as post-harvest treatment for minimally processed Fuji apples. Innov. Food Sci. Emerg. Technol. 33, 589-595. https://doi.org/10.1016/j.ifset.2015.10.004.
Barbieri, R., Coppo, E., Marchese, A., Daglia, M., Sobarzo-Sánchez, E., Nabavi, S.F., and Nabavi, S.M. (2017). Phytochemicals for human disease: An update on plant-derived compounds antibacterial activity. Microbiol. Res. 196, 44-68. https://doi.org/10.1016/j. micres.2016.12.003.

Bartolini, S., and Ducci, E. (2017). Quality evaluation of local apple varieties: Physicochemical and antioxidant proprieties at harvest and after cold storage. Agron. Res. 15, 1866-1877.

Bartolini, S., Orlando, M., Trivellini, A., Venturi, F., Sanmartin, C., Taglieri, I., Macaluso, M., Zinnai, A., and Mensuali-Sodi, A. (2020). The residues of fruit and vegetable processing: From "waste" to "resource" of natural phytochemical compounds. Adv. Hortic. Sci. 34, 35-42.

Cerutti, A.K., Bruun, S., Donno, D., Beccaro, G.L., and Bounous, G. (2013). Environmental sustainability of traditional foods: The case of ancient apple cultivars in Northern Italy assessed by multifunctional LCA. J. Clean. Prod. 52, 245-252. https://doi.org/10.1016/j. jclepro.2013.03.029.

Chiabrando, V., and Giacalone, G. (2012). Effect of antibrowning agents on color and related enzymes in fresh-cut apples during cold storage. J. Food Process. Preserv. 36, 133-140. https://doi. org/10.1111/j.1745-4549.2011.00561.x.

Chinnici, F., Gaiani, A., Natali, N., Riponi, C., and Galassi, S. (2004). Improved HPLC determination of phenolic compounds in cv. 'Golden Delicious' apples using a monolithic column. J. Agric. Food Chem. 52, 3-7. https://doi.org/10.1021/jf030459n.

Colás-Medà, P., Abadias, M., Altisent, R., Alegre, I., Plaza, L., Gilabert, V., Lacomba, R., and Viñas, I. (2016). Development of a fresh-cut product based on pears and the subsequent evaluation of its shelf life under commercial conditions and after a cold chain break. J. Food Nutr. Res. 4, 582-591.

Contini, M., Baccelloni, S., Massantini, R., and Anelli, G. (2008). Extraction of natural antioxidants from hazelnut (Corylus avellana L.) shell and skin wastes by long maceration at room temperature. Food Chem. 110, 659-669. https://doi.org/10.1016/j. foodchem.2008.02.060.

Dávila-Aviña, J.E., Solís-Soto, L.Y., Rojas-Verde, G., and Salas, N.A. (2015). Sustainability and challenges of minimally processed foods. In Minimally Processed Foods, M.W. Siddiqui, and M.S. Rahman, eds. (Springer), p. 279-295. https://doi.org/10.1007/978-3-31910677-9_12.

Delgado-Adámez, J., Fernández-León, M.F., Velardo-Micharet, B., and González-Gómez, D. (2012). In vitro assays of the antibacterial and antioxidant activity of aqueous leaf extracts from different Prunus salicina Lindl. cultivars. Food Chem. Toxicol. 50, 2481-2486. https:// doi.org/10.1016/j.fct.2012.02.024.

Fratianni, F., Coppola, R., and Nazzaro, F. (2011). Phenolic composition and antimicrobial and antiquorum sensing activity of an ethanolic extract of peels from the Apple cultivar 'Annurca'. J. Med. Food 14,957-963. https://doi.org/10.1089/jmf.2010.0170.

Liu, X., Yang, Q., Lu, Y., Li, Y., Li, T., Zhou, B., and Qiao, L. (2019). Effect of purslane (Portulaca oleracea L.) extract on anti-browning of freshcut potato slices during storage. Food Chem. 283, 445-453. https:// doi.org/10.1016/j.foodchem.2019.01.058.

Ma, L., Zhang, M., Bhandari, B., and Gao, Z. (2017). Recent developments in novel shelf life extension technologies of fresh-cut fruits and vegetables. Trends Food Sci. Technol. 64, 23-38. https:// doi.org/10.1016/j.tifs.2017.03.005.

Manzoor, M., Anwar, F., Saari, N., and Ashraf, M. (2012). Variations of antioxidant characteristics and mineral contents in pulp and peel of different apple (Malus domestica Borkh.) cultivars from Pakistan. Molecules 17, 390-407. https://doi.org/10.3390/ molecules17010390. 
Meireles, A., Giaouris, E., and Simões, M. (2016). Alternative disinfection methods to chlorine for use in the fresh-cut industry. Food Res. Int. 82, 71-85. https://doi.org/10.1016/j.foodres.2016.01.021.

Olivas, G.I., Mattinson, D.S., and Barbosa-Cánovas, G.V. (2007). Alginate coatings for preservation of minimally processed 'Gala' apples. Postharvest Biol. Technol. 45, 89-96. https://doi. org/10.1016/j.postharvbio.2006.11.018.

Ortiz, A., Graell, J., and Lara, I. (2011). Cell wall-modifying enzymes and firmness loss in ripening 'Golden Reinders' apples: A comparison between calcium dips and ULO storage. Food Chem. 128, 1072-1079. https://doi.org/10.1016/j.foodchem.2011.04.016.

Putnik, P., Roohinejad, S., Greiner, R., Granato, D., Bekhit, A.E.D.A., and Bursać Kovačević, D. (2017). Prediction and modeling of microbial growth in minimally processed fresh-cut apples packaged in a modified atmosphere: A review. Food Control 80, 411-419. https:// doi.org/10.1016/j.foodcont.2017.05.018.

Rojas-Graü, M.A., Sobrino-López, A., Soledad Tapia, M., and MartínBelloso, 0. (2006). Browning inhibition in fresh-cut 'Fuji' apple slices by natural antibrowning agents. J. Food Sci. 71, S59-S65. https://doi. org/10.1111/j.1365-2621.2006.tb12407.x.

Saltveit, M.E. (2016). The three responses of plant tissue to wounding. Acta Hortic. 1141, 13-20. https://doi.org/10.17660/ ActaHortic.2016.1141.2.

Sanmartin, C., Taglieri, I., Macaluso, M., Sgherri, C., Ascrizzi, R., Flamini, G., Venturi, F., Quartacci, M.F., Luro, F., Curk, F., et al. (2019). Cold-pressing olive oil in the presence of cryomacerated leaves of olea or citrus: Nutraceutical and sensorial features. Molecules 24(14), 2625. https://doi.org/10.3390/molecules24142625.

Schuh, V., Schuh, J., Fronza, N., Foralosso, F.B., Verruck, S., Vargas Junior, A., and da Silveira, S.M. (2020). Evaluation of the microbiological quality of minimally processed vegetables. Food Sci. Technol. 40, 290-295. https://doi.org/10.1590/fst.38118.

Stepanović, S., Antić, N., Dakić, I., and Švabić-Vlahović, M. (2003). In vitro antimicrobial activity of propolis and synergism between propolis and antimicrobial drugs. Microbiol. Res. 158, 353-357. https://doi.org/10.1078/0944-5013-00215.

Vardanega, R., Prado, J.M., and Meireles, M.A.A. (2015). Adding value to agri-food residues by means of supercritical technology. J. Supercrit. Fluids 96, 217-227. https://doi.org/10.1016/j. supflu.2014.09.029.

Venturi, F., Andrich, G., Sanmartin, C., Taglieri, I., Serni, E., and Zinnai, A. (2015). Winemaking of Sangiovese grapes with and without the addition of different oenological tannins in order to increase the colour intensity of Chianti wine. Agrochimica 59, 261-271.

Venturi, F., Sanmartin, C., Taglieri, I., Xiaoguo, Y., Quartacci, M.F., Sgherri, C., Andrich, G., and Zinnai, A. (2017). A kinetic approach to describe the time evolution of red wine as a function of packaging conditions adopted: Influence of closure and storage position Food Pack. Shelf Life 13, 44-48. https://doi.org/10.1016/j. fpsl.2017.07.001.

Venturi, F., Bartolini, S., Sanmartin, C., Orlando, M., Taglieri, I., Macaluso, M., Lucchesini, M., Trivellini, A., Zinnai, A., and Mensuali, A. (2019). Potato peels as a source of novel green extracts suitable as antioxidant additives for fresh-cut fruits. Appl. Sci. 9(12), 2431. https://doi.org/10.3390/app9122431.

Waldbauer, K., McKinnon, R., and Kopp, B. (2017). Apple pomace as potential source of natural active compounds. Planta Med. 83, 9941010. https://doi.org/10.1055/s-0043-111898.

Wang, W., and Kannan, K. (2019). Quantitative identification of and exposure to synthetic phenolic antioxidants, including butylated hydroxytoluene, in urine. Environm. Int. 128, 24-29. https://doi. org/10.1016/j.envint.2019.04.028.
Witkowska, A.M., Hickey, D.K., Alonso-Gomez, M., and Wilkinson, M. (2013). Evaluation of antimicrobial activities of commercial herb and spice extracts against selected food-borne bacteria. J. Food Res. 2, 37. https://doi.org/10.5539/jfr.v2n4p37.

Yousuf, B., Qadri, O.S., and Srivastava, A.K. (2018). Recent developments in shelf-life extension of fresh-cut fruits and vegetables by application of different edible coatings: A review. LWT- Food Sci. Technol. 89, 198-209. https://doi.org/10.1016/j.lwt.2017.10.051.

Zhang, J., Wen, C., Zhang, H., Duan, Y., and Ma, H. (2020). Recent advances in the extraction of bioactive compounds with subcritical water: A review. Trends Food Sci. Technol. 95, 183-195. https://doi. org/10.1016/j.tifs.2019.11.018.

Received: Apr. 1, 2021

Accepted: Sep. 21, 2021

Addresses of authors:

S. Bartolini ${ }^{1}$, L. Pozzo ${ }^{2}$, F. Venturi ${ }^{3,4}$, C. Sanmartin ${ }^{3,4}$,

I. Taglieri ${ }^{3, *}$, M. Macaluso ${ }^{3}$, A. Trivellini ${ }^{1}$, M. Orlando ${ }^{1}$,

A. Zinnai ${ }^{3,4}$ and A. Mensuali Sodi ${ }^{1}$

${ }^{1}$ Institute of Life Sciences, Scuola Superiore Sant'Anna,

Piazza Martiri della Libertà 33, 56127, Pisa, Italy

2 Institute of Agricultural Biology and Biotechnology, NRC, Pisa, Italy

${ }^{3}$ Department of Agriculture, Food and Environment, University of Pisa, Via del Borghetto 80, 56124, Pisa, Italy

${ }^{4}$ Interdepartmental Research Center Nutrafood-

Nutraceuticals and Food for Health, University of Pisa,

Pisa, Italy

*Corresponding author; E-mail: isabella.taglieri@unipi.it 